\title{
Monitoring DNAPL Pumping Using Integrated Geophysical Techniques
}

\author{
R.L. Newmark \\ W.D. Daily \\ K.R. Kyle \\ A.L. Ramirez
}

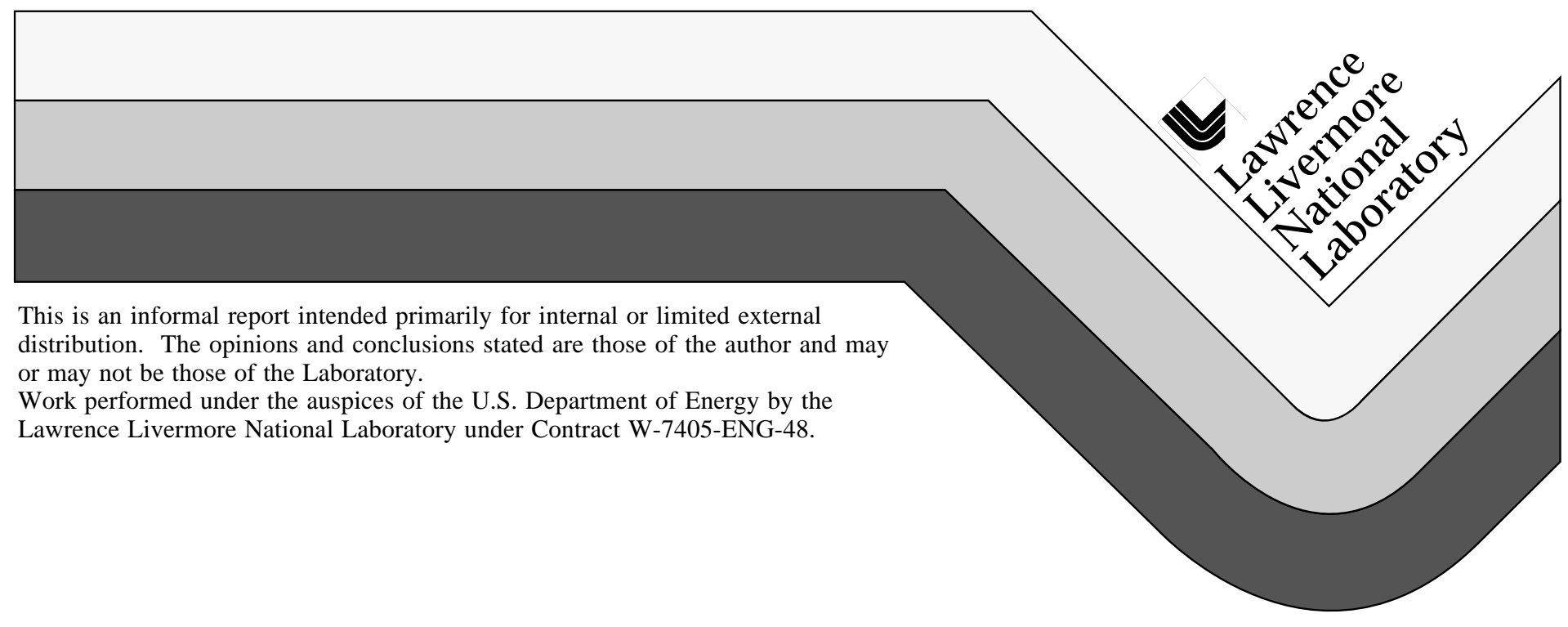




\section{DISCLAIMER}

This document was prepared as an account of work sponsored by an agency of the United States Government. Neither the United States Government nor the University of California nor any of their employees, makes any warranty, express or implied, or assumes any legal liability or responsibility for the accuracy, completeness, or usefulness of any information, apparatus, product, or process disclosed, or represents that its use would not infringe privately owned rights. Reference herein to any specific commercial product, process, or service by trade name, trademark, manufacturer, or otherwise, does not necessarily constitute or imply its endorsement, recommendation, or favoring by the United States Government or the University of California. The views and opinions of authors expressed herein do not necessarily state or reflect those of the United States Government or the University of California, and shall not be used for advertising or product endorsement purposes.

This report has been reproduced directly from the best available copy.

Available to DOE and DOE contractors from the Office of Scientific and Technical Information

P.O. Box 62, Oak Ridge, TN 37831

Prices available from (615) 576-8401, FTS 626-8401

Available to the public from the

National Technical Information Service

U.S. Department of Commerce 5285 Port Royal Rd.,

Springfield, VA 22161 


\title{
Monitoring DNAPL Pumping Using Integrated Geophysical Techniques
}

\author{
Robin L. Newmark, William D. Daily, Kevin R. Kyle and Abelardo L. Ramirez \\ Lawrence Livermore National Laboratory, Livermore, California, 94550
}

\begin{abstract}
The removal of DNAPL during pumping has been monitored using integrated in situ geophysical techniques. At Hill Air Force Base in Utah, a free-product DNAPL plume (consisting predominantly of TCE) is pooled in water-wet soil on a thick clay aquitard. Groundwater pumping at Operable Unit 2 (OU 2) began in 1994; to date, nearly 30,000 gallons of DNAPL have been recovered from the site. From September, 1994 through September, 1995, changes in the basin during DNAPL pumping were monitored using fiber optic chemical sensors, neutron logs and electrical resistance tomography (ERT). Fiber optic sensors and neutron logs verify the presence of DNAPL in the vicinity of three boreholes which form a cross section from the perimeter of the basin to its center. Cross borehole ERT images the changes in formation electrical properties due to the removal of DNAPL, extending the understanding of DNAPL removal between the boreholes. During pumping, electrical resistivities decreased; we suggest that these decreases are directly caused by the reduction in DNAPL. During ground water pumping, water with relatively low resistivity replaces some of the DNAPL pockets as the highly insulating DNAPL is removed. The results suggest that, as DNAPL is pumped from a nearby well, product slowly drains along the top of an aquitard and into the pump well, where it collects.
\end{abstract}

\section{Introduction}

At Hill Air Force Base in northern Utah, free-product DNAPL (consisting predominantly of TCE) was found to be pooled in water-wet soil on a thick clay aquitard. Spent liquid degreasing solvents were disposed of in unlined trenches at the site, now known as Operable Unit 2 (OU 2), resulting in pools of DNAPL (primarily TCE, but also containing TCA, PCE and methylene chloride) which accumulated along the base of the uppermost aquifer. The DNAPL pools and the residual DNAPL saturation within the aquifer constitute a source for ground water contamination and off-site migration of dissolved contaminants.

The site has been characterized by over 150 soil borings, many of which were completed as recovery wells or piezometers. Details of the site characterization can be found in the Remedial Investigations reports (Radian Corp., 1992, 1993). The aquifer is composed of interbedded silts, sands and gravels of the Provo Formation. The aquitard consists of laminated clay with occasional thin sand and silt interlaminae of the Alpine Formation, which is thought to continue for hundreds of feet. The surface of the top of the aquitard is irregular, and may represent an erosional surface along which the coarser-grained deposits of the Provo Formation were deposited. The DNAPL has accumulated in depressions along this surface, forming two pools. The aquifer is elongated from north to south with apparent impermeable boundaries to the east and west. Hillside slumping (in an easterly 
direction) contributes to the local stratigraphic complexity. Ground water occurs at about $20 \mathrm{ft}$ below ground surface in the uppermost unconfined aquifer.

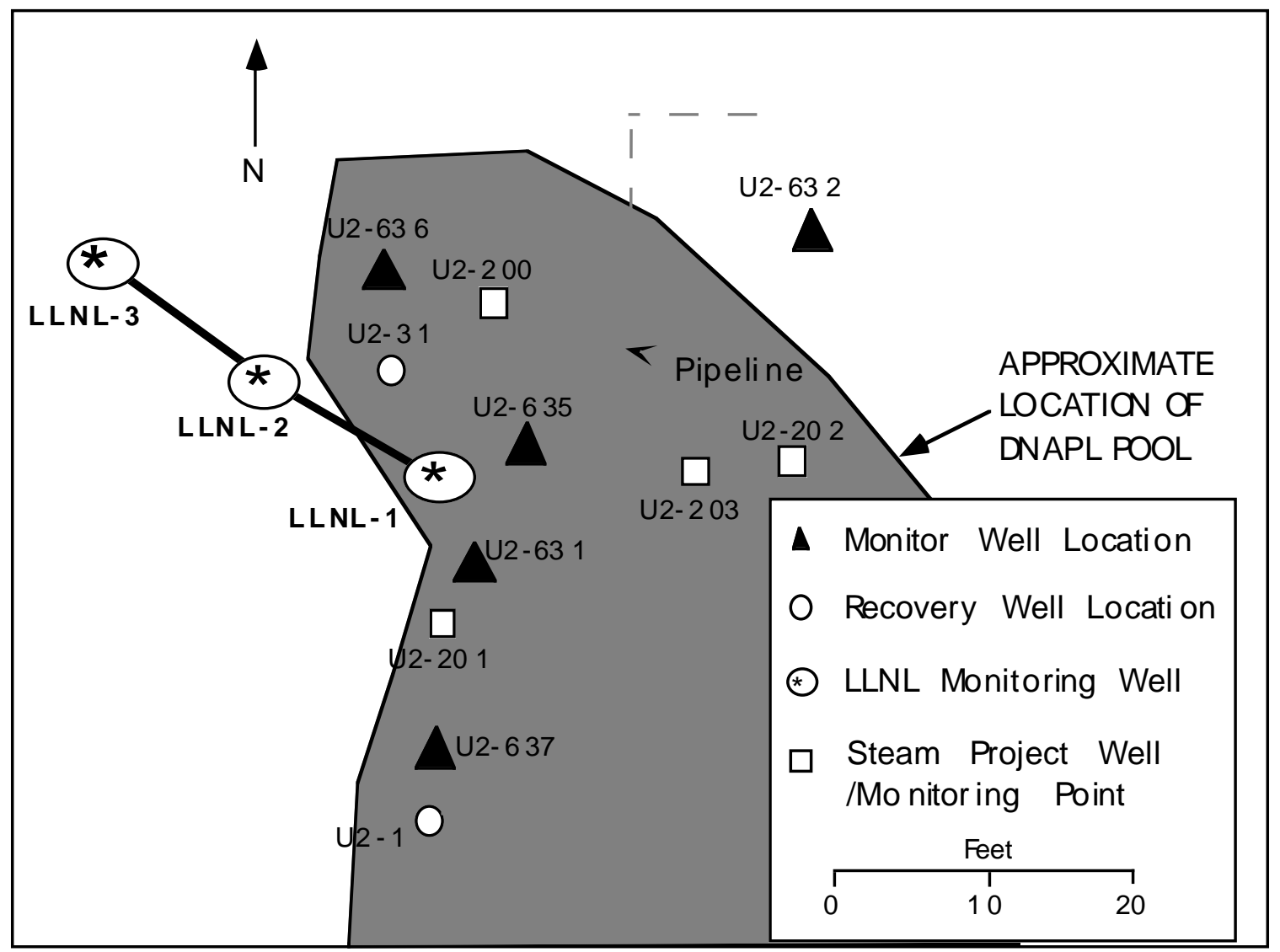

Figure 1. Site map, showing the location of monitoring wells and the outline of the approximate lateral extent of the northerly DNAPL pool (after Radian, 1992). Well locations are taken from the SAIC site map.

A pump and treat system was constructed for the removal of DNAPL and to reduce offsite migration of contaminated ground water. A detail of the site layout is shown in Figure 1. Pumping at OU 2 began in October, 1993; to date, nearly 30,000 gallons of DNAPL have been recovered from the site. Wells U2-31 and U2-1 are the primary pumping wells in the northerly pool. Oolman and his colleagues (1995) have described this system and its operations in detail. Initial recovery rates were high, and approximately 23,000 gallons of separate phase DNAPL were removed in the first nine months of operation. In addition, over one million gallons of contaminated ground water were recovered, treated and discharged.

The primary DNAPL recovery in the northern pool was completed just prior to the start of this study. By August, 1994, recovery rates had dropped two to three orders of magnitude from the initial recovery rates of over 1000 gallons a day in late 1993 and DNAPL levels had dropped overall (Figure 2a). As pumping operations continued, a pattern emerged in the well response, one indicative of slow drainage toward residual saturation. DNAPL levels in pumping well U2-31 dropped during pumping, and recovered soon after pumping 
ceased. This is readily apparent in the data recorded in March and April, 1995 (Figure 2b). Baseline DNAPL levels in U2-31 and monitor well U2-635 were at their highest on Mondays; levels dropped as pumping began, and remained low throughout the week, in some cases the DNAPL level ran dry in nearby monitoring wells. DNAPL observed in the recovered ground water decreased during each pumping cycle as well. Pumps were shut off on Fridays, and the DNAPL levels recovered in U2-31 during the weekend to nearly their previous Monday value. DNAPL levels in U2-635 often dropped at the end of a pumping interval. Although the U2-31 DNAPL levels appeared to recover each weekend, examination of the long-term levels shows that the overall DNAPL level continues to drop over time.

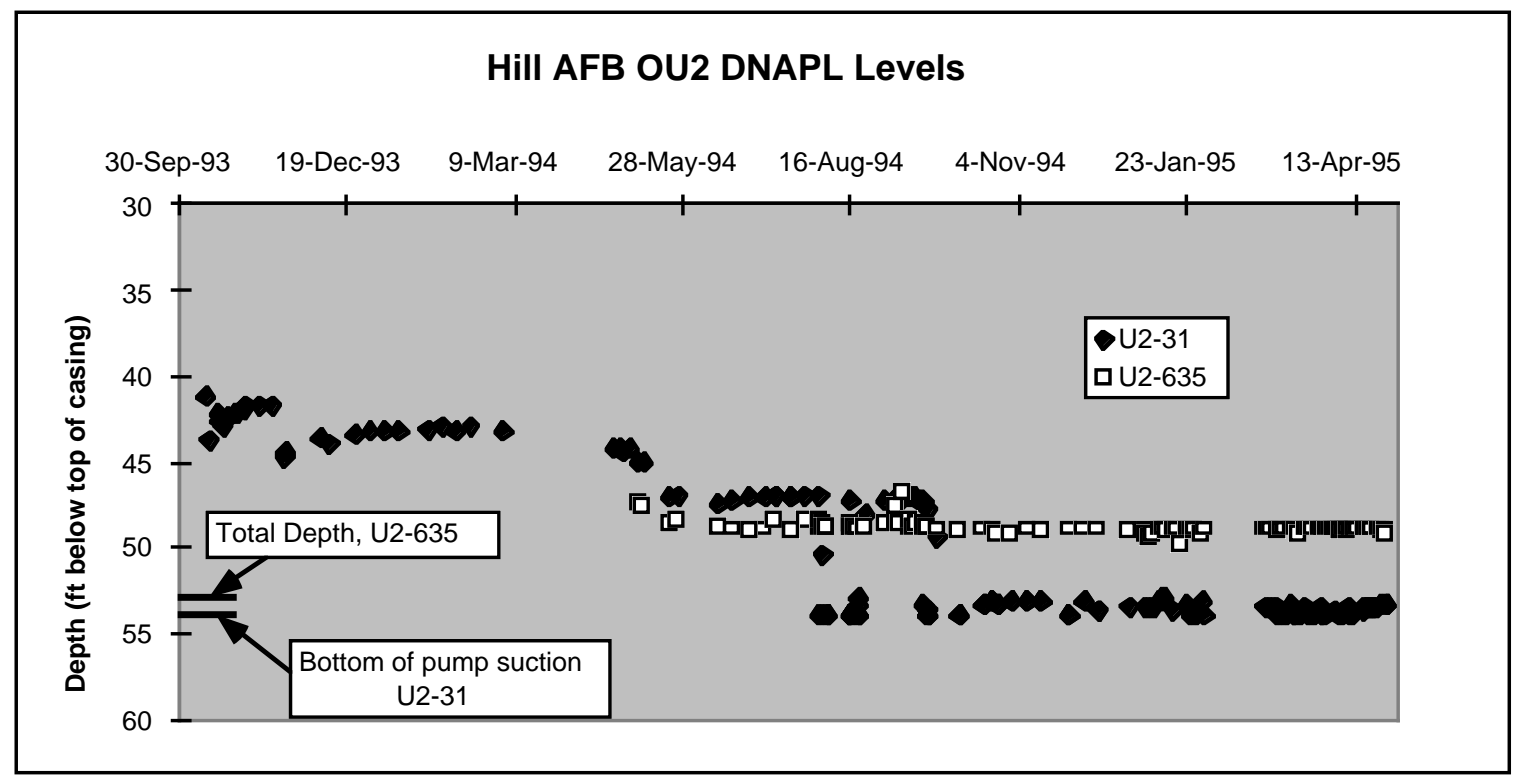

Figure 2a. DNAPL levels, generally measured in the mornings. 


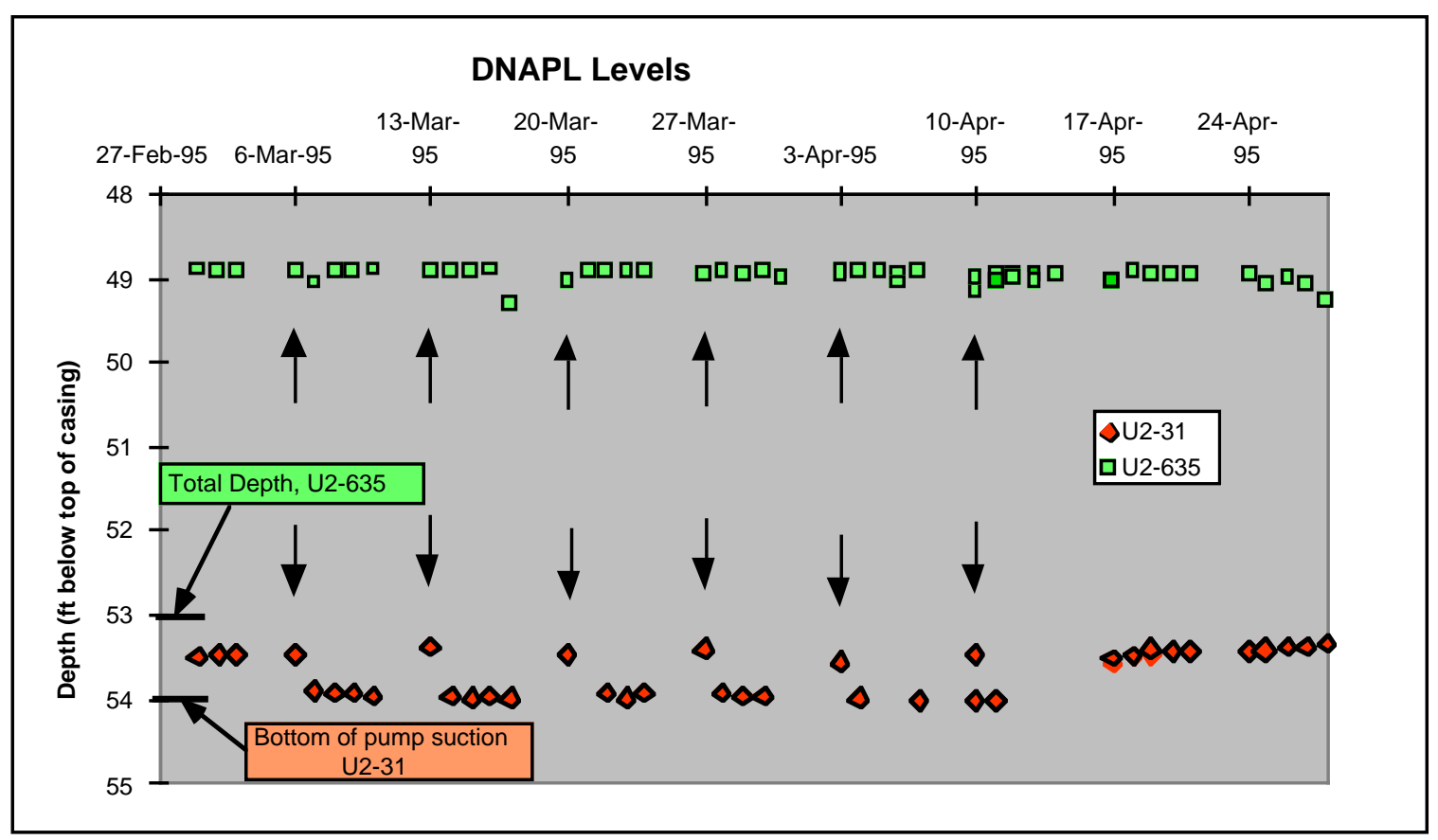

Figure 2b. DNAPL levels. Arrows indicate recovery levels attained as of Monday mornings after pumping was terminated on the previous Friday. 
$9 / 1 / 94$

rev1

$12 / 96$

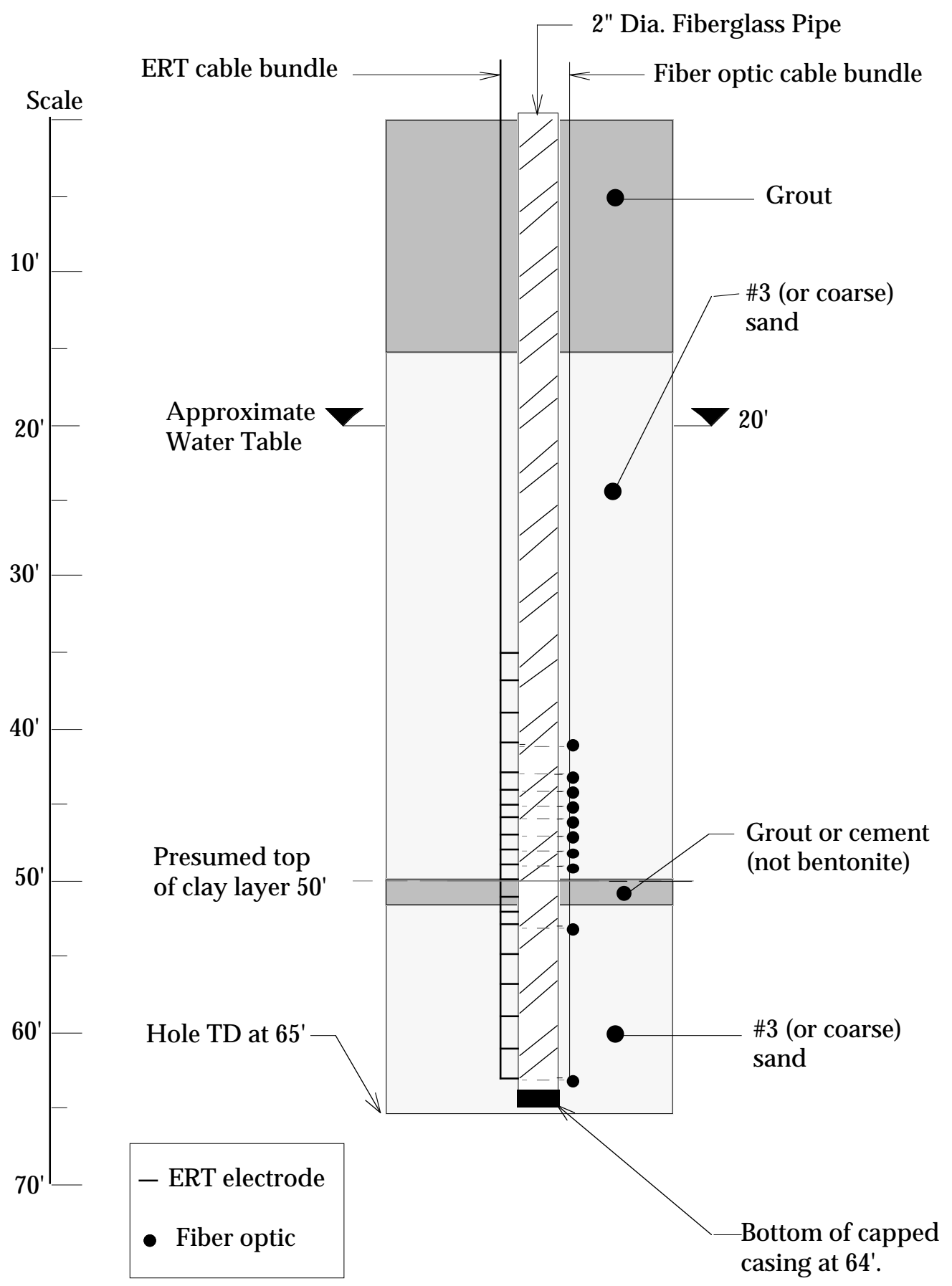

Note: Instrumentation strings to be installed over the same depth interval in all 3 wells.

Figure 3. Monitoring well design for LLNL wells at Hill Air Force Base. 
In September, 1994, three multipurpose monitoring boreholes were installed at OU 2 for the purpose of monitoring the geophysical changes due to DNAPL pumping. Each borehole consists of fiberglass casing (nominally 2" diameter), instrumented with electrical resistance tomography (ERT) electrodes and fiber optic sensors. Figure 3 shows the generalized well description, including the instrumentation. The monitoring wells form a line across the DNAPL pool; LLNL-1 was located directly within the pool, LLNL-2 was located about $15 \mathrm{ft}$. away along the edge of the pool, and LLNL-3 was positioned about 20 $\mathrm{ft}$. further along, outside the affected area. The monitoring boreholes each contain 20 electrodes used to perform crosshole resistivity surveys in the depth range of 40 to $64 \mathrm{ft}$. They also contain 10 fiber optic sensors used to verify the presence of DNAPLs at discrete points from 43 to $65 \mathrm{ft}$. The three LLNL wells are numbered in spatial order, from east to west reaching from the center of the DNAPL plume out toward the periphery; this differs from the Radian driller's logs, which number the wells in the order drilled. Thus, the driller's logs have LLNL-2 and LLNL-3 reversed.

\section{Baseline Data}

Baseline geophysical and fiber optic data were collected during the second week of September, 1994. Neutron, resistivity and gamma logs were collected at this time. Since this report's focus is the changes observed due to ground water pumping, although logs were obtained from surface to total depth, we will focus on the data obtained below the water table.

The induction logs are strongly affected by the presence of metal electrodes along the LLNL monitoring wells. The resulting logs are greatly diminished in magnitude and show strong spikes in the vicinity of the electrodes; they are not reproduced here. However, the electrical properties of the formation are clearly delineated in the ERT images, discussed later in this report.

The lithologic logs are based on visual descriptions of cores obtained approximately every $5 \mathrm{ft}$ and qualitative indicators (cuttings, driller's comments, etc.). The depths of the lithologic boundaries are thus only accurate to $+/-5 \mathrm{ft}$. The geophysical logs give a more reliable, continuous indication of lithology. The gamma logs showed general correlation with the lithology; greater counts in the more clay-rich zones (Figure 4a). The lithologic boundary at the base of a sandy region at $50 \mathrm{ft}$. in LLNL-1 appears to be rather sharp; the gamma counts rise from about 100 to nearer 150 ove

The neutron logs (Figure 4b) exhibit the highest counts in the vicinity of the water table, from about $13 \mathrm{ft}$ to about $27 \mathrm{ft}$ depth. The high neutron counts might be interpreted as resulting from sandy and/unsaturated material. However, the lithologic information indicates that the westerly two wells are nearly entirely composed of silt and clay. The neutron counts are expected to decrease in the presence of water or chlorinated hydrocarbons, due to the neutron cross section of hydrogen and chlorine. Neutron counts decrease in LLNL-1 at about 18-22 ft and at 24-25 ft depth. During drilling, there was

evidence of a water table at about $21.5 \mathrm{ft}$ in LLNL-1. In LLNL-2, there is a similar decrease in neutron counts at about 18-21 ft, and a much smaller one at about 25-26 ft. There was no real indication of a water table in LLNL-2 during drilling, although it was expected at about $20 \mathrm{ft}$. In LLNL-3, there is a similar zone of high neutron counts from 
about 13-27 ft, but there are no intervals of decreased counts within it. No clear evidence of a water table was found at LLNL-3 during drilling. It is possible that the short intervals where the neutron counts decrease in LLNL-1 and LLNL-2 found at about 21 and $24 \mathrm{ft}$ are related to the presence of current or past groundwater contamination in the vicinity of the water table; without additional information, this is merely a supposition.
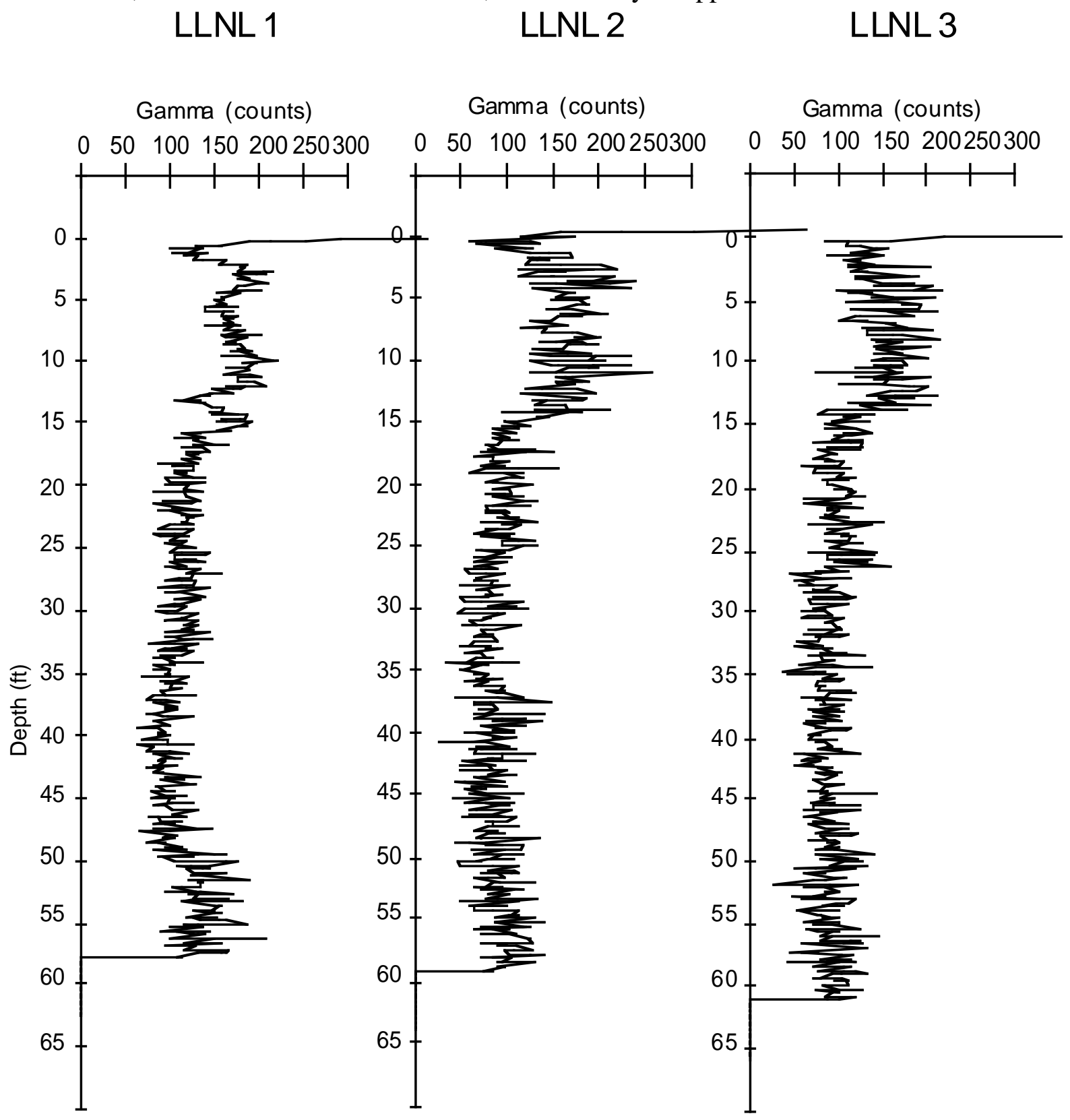

Figure 4a. Gamma logs obtained in LLNL wells.

The neutron logs were run to provide a more detailed indication of the vertical extent of DNAPL contamination along the boreholes. Since the water table is at about $20 \mathrm{ft}$., the region of interest is expected to be fully saturated. Therefore, the neutron signal will primarily indicate variations in chemical character and porosity. A zone of decreased neutron counts occurs from about 45 $52 \mathrm{ft}$ depth in LLNL-1, in which a lithologic boundary from sandy to clay-rich material occurs 
at about $50 \mathrm{ft}$. The character of this feature in the neutron log is much broader than that expected from the lithologic contrast at the base of the sandy region. The gamma logs show no indication of a lithologic gradient over this zone; the boundary appears quite sharp. This decrease likely results from the increase in chlorinated components in the fluids saturating the soil; the neutron log is responding to chlorine-laden DNAPL in the vicinity of the borehole.

LLNL 1

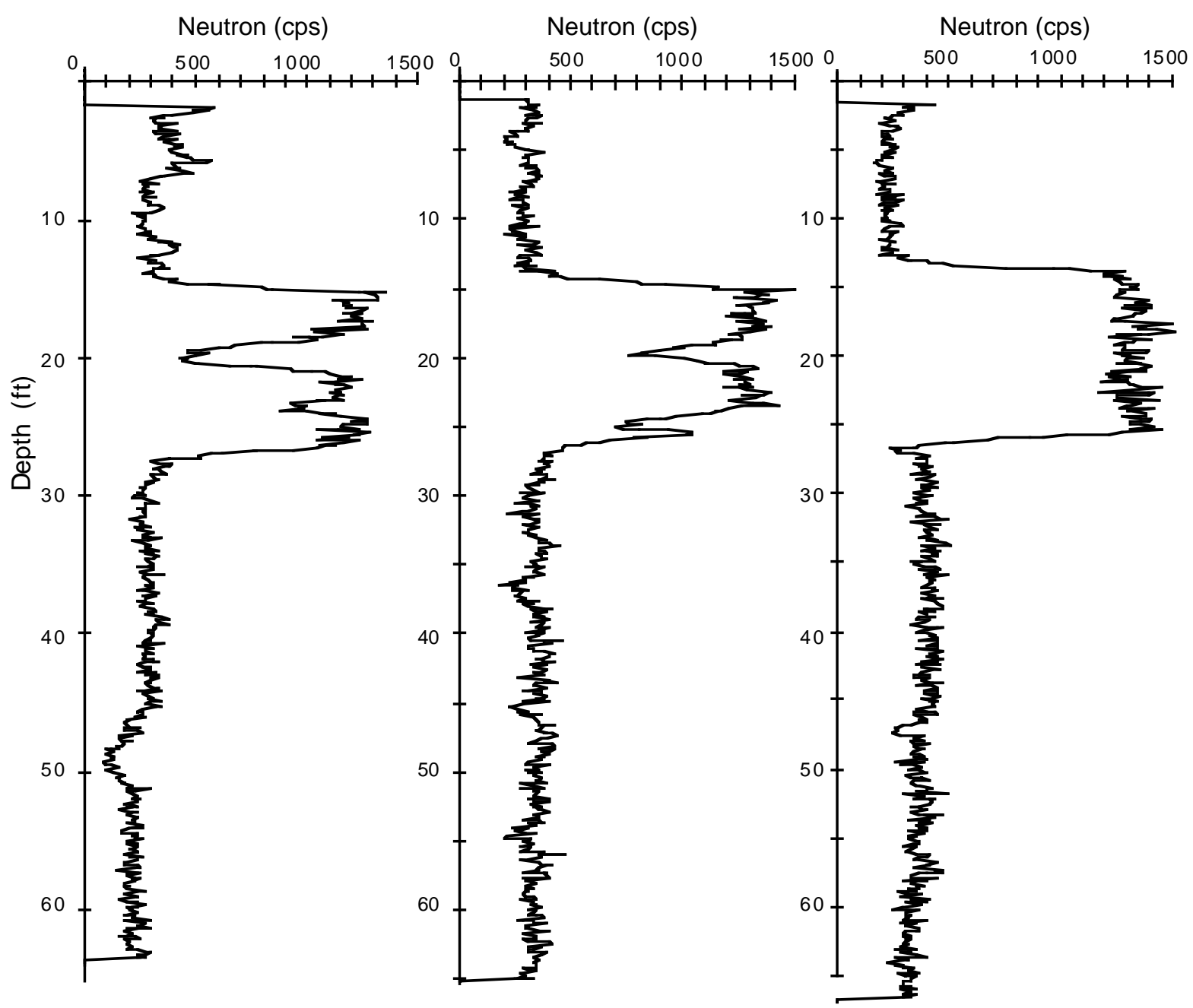

Figure 4b. Neutron logs obtained in LLNL wells.

There is a small zone of decreased neutron counts from about 45 - $48 \mathrm{ft}$ depth in well LLNL-2; this correlates with the interval in which the fiber optic sensors indicate the presence of small or residual quantities of DNAPL. In LLNL-3, a small zone $(\sim 1 \mathrm{ft})$ of decreased neutron counts at about $47 \mathrm{ft}$ depth in LLNL-3 similarly correlates with the fiber optic sensors' indication of small or residual quantities of DNAPL.

Electrical resistance tomography (ERT) has been demonstrated to be a useful characterization tool, providing details of the lithostratigraphy between wells (e.g., Newmark et al., 1994). ERT has previously been used to map subsurface processes such as fluid infiltration (Daily et al., 1992), steam injection and ohmic heating (Ramirez et al., 
1993, 1995) by mapping the spatial and temporal changes in soil resistivity resulting from changes in liquid saturation and temperature. The presence of appreciable amounts of separate-phase, electrically insulating DNAPL at OU 2 should locally increase electrical resistivity (TCE, which constitutes about $60 \%$ of the DNAPL, has an electrical resistivity of 1.25 MOhm-m). The removal of DNAPL during pumping should produce a drop in

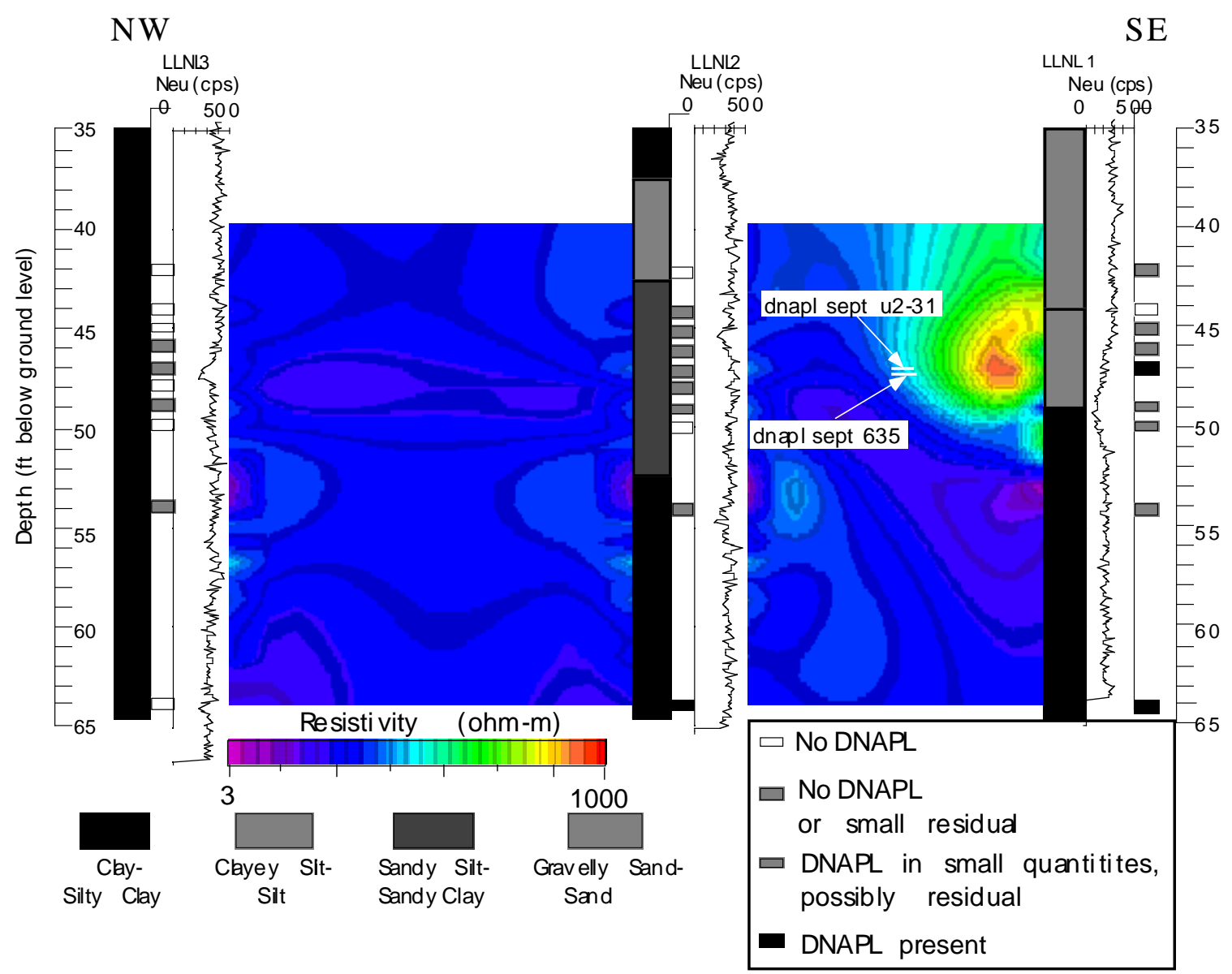

Figure 5a. Baseline ERT images, shown with neutron logs and fiber optic sensor data. The small rectangles indicate the location of the fiber optic sensors. DNAPL levels measured in U2-31 and U2-635 are also shown.

electrical resistivity, as the insulating fluids are displaced by relatively conductive groundwater.

The method of ERT data collection and processing has been described in detail by Ramirez and his colleagues (e.g., Ramirez et al., 1995). Figures 5a and 5b display the baseline data. The ERT images present a bowl-shaped resistive zone, with a sharply defined western wall. The shape of the resistive anomaly is centered about an extremely resistive spot at about $47 \mathrm{ft}$ depth, just to the west of LLNL-1, rather than suggesting a flat-lying or dipping sequence of layers. A sandy region present between depths of 39 and $45 \mathrm{ft}$ corresponds to the region with the highest resistivities in the ERT images. Along wells LLNL-2 and LLNL-3, there is no obvious correlation between the lithology and the resistivity structure. The lithologic logs, based on visual inspection of infrequently obtained core samples 
(approximately every $5 \mathrm{ft}$ ) and driller's input provide only a rough idea of the formation lithology. The lack of correlation may reflect the more qualitative understanding of the true formation characteristics or the fact that visual descriptions of core cannot be used to reliably establish the soil electrical properties.

NW

SE

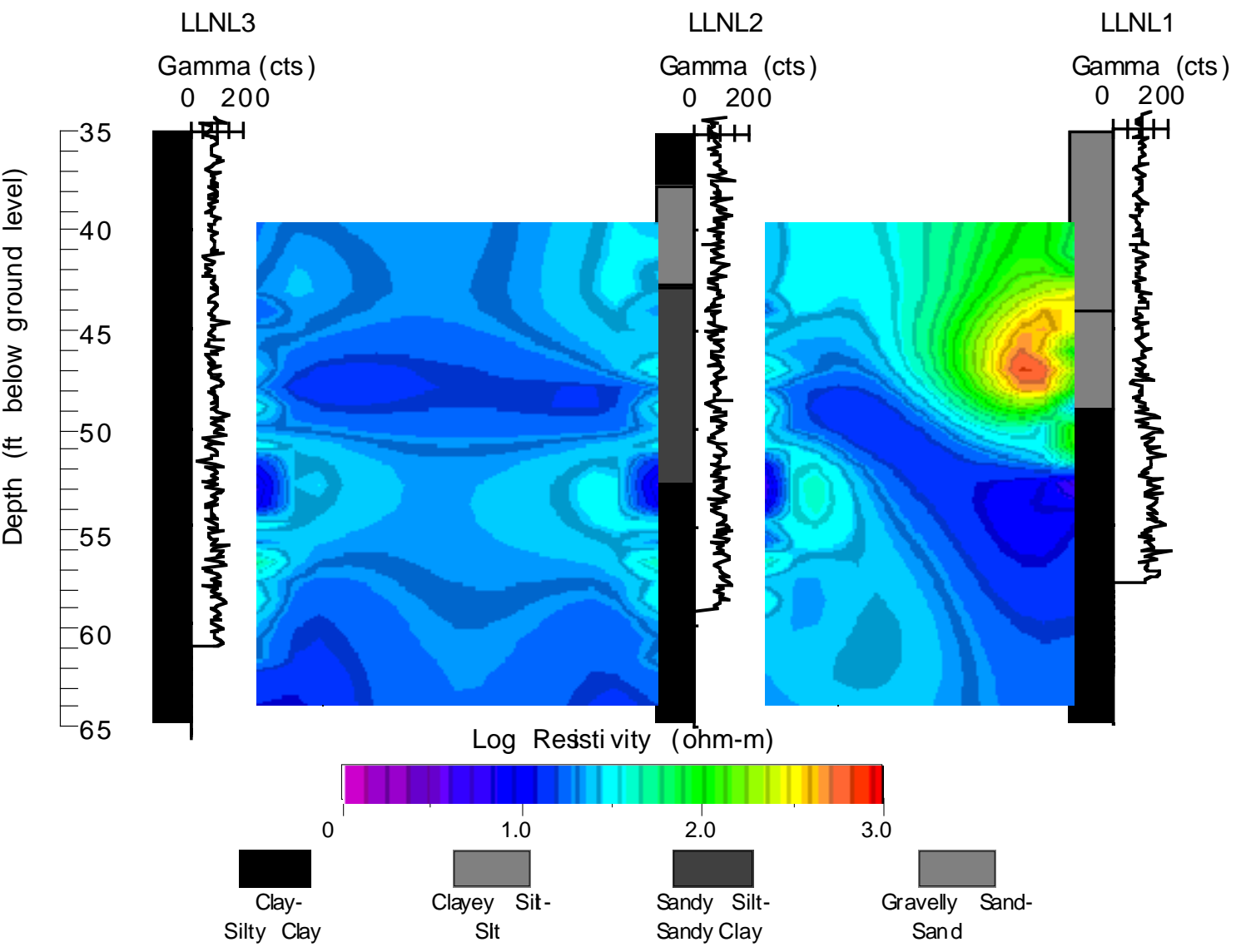

Figure 5b. Baseline ERT images shown with gamma logs and lithology as indicated by the drilling geologist.

Figure 5b compares the ERT baseline images with the lithology and gamma logs; the scale used for the resistivity images is smaller than that used in Figure 5a in order to enhance the resistivity contrast between holes LLNL-2 and LLNL-3. The resistivity structure between holes LLNL-2 and LLNL-3 suggests continuous, almost flat lying layers. The resistivity structure is different in the upper half of the image between LLNL-1 and LLNL-2; here it is not layered but rather bowl-shaped. The base of the sandy region indicated by the lithologic logs differs from that suggested by the ERT images. This is probably because the lithologic logs are based on infrequent core samples (obtained every $5 \mathrm{ft}$ ). Also notice the region of low resistivity that cuts across both images near the center of Figure $5 \mathrm{~b}$; this 
region is roughly spoon- shaped. The "spoon handle" is centered at a depth of $48 \mathrm{ft}$. and oriented horizontally, between LLNL-3 and LLNL-2; the "spoon bowl" is located close to LLNL-1 and is centered at a depth of $55 \mathrm{ft}$. Nearly all fiber optic sensors indicating free product DNAPL are located either within or above this region of low resistivity. The low resistivity suggests that this spoon shaped feature may be particularly clay-rich; it may serve as a barrier to downward DNAPL migration.

The presence of DNAPL was detected by laser induced photoluminescence. The fiber optic chemical sensors detect the presence of OU 2 DNAPL due to its strong fluorescence. Excitation from a $488 \mathrm{~nm}$ air cooled Argon ion laser was delivered to the in situ interrogation site via a $200 \mu \mathrm{m}$ optical fiber. Any emission generated by DNAPL was collected using a second $200 \mu \mathrm{m}$ optical fiber which transferred signal to the surface where it was detected using a photodiode detector and a lock-in amplifier. The collected emission was separated from reflected laser light with a $580 \mathrm{~nm}$ band pass filter which coincides with the DNAPL emission maximum. Laboratory measurements on soil core samples demonstrated that the soil itself (clay, silts, and sand) was nonemissive when impinged upon by $488 \mathrm{~nm}$ laser excitation. The native ground water was also shown to be nonemissive. Fortuitously, regions in the soil samples where DNAPL had resided became nonemissive when the DNAPL was washed away and replaced by ground water. Thus, the presence of emission would conclusively indicate the presence of DNAPL. The intensity of luminescence detected is taken to be indicative of the amount of DNAPL present in the soil and groundwater adjacent to the sensor. The estimated radius of investigation for the sensor is on the order of millimeters.

The fiber optic sensors indicate free product DNAPL is present at LLNL-1 at $47 \mathrm{ft}$, within the sandy region. Other fiber optic sensors along LLNL-1 show indications of residual DNAPL within the sandy region. There is evidence of residual DNAPL along LLNL-2 between 47 and $48 \mathrm{ft}$ and along LLNL-3 at about $46 \mathrm{ft}$. The varying concentrations of DNAPL indicated by sensors located in close proximity suggests that the DNAPL forms pockets within the porous medium rather than a continuous layer.

\section{Changes During Pumping: January, 1995}

In January, 1995, a second set of ERT and fiber optic sensor data was collected. Between September, 1994 and January, 1995, 643 gallons of DNAPL had been recovered. Nearly 500,000 gallons of treated water had been transferred off site. DNAPL levels dropped substantially in November and December, 1994; a considerable change was expected in the basin, and a repeat measurement trip was scheduled. The precipitous drop in DNAPL level was not permanent, however; in retrospect, it may have been partly due to the drilling activities during the emplacement of the steam injection wells in the area. In any case, the DNAPL level in U2-31 (the pumping well), had dropped about $6 \mathrm{ft}$ total between September and January; however, the total DNAPL level decrease in monitor well U2635 , only a few feet away, was about $0.8 \mathrm{ft}$.

The January results are shown in Figure 6 as both absolute images and differences between the January and September results. Electrical resistivities decreased by hundreds of ohm$\mathrm{m}$ in the sandy region near borehole LLNL-1 at $47 \mathrm{ft}$. depth; the region between holes LLNL-2 and LLNL-3 shows basically no changes. DNAPL concentrations decreased at 
most of the fiber optic sensors located above $49 \mathrm{ft}$. These locations are coincidentally above the spoon-shaped zone of low electrical resistivity that we suggest is acting as a confining layer. The greatest change in DNAPL concentration indicated by a fiber optic sensor was in borehole LLNL-1 at a depth of $47 \mathrm{ft}$. The largest resistivity decreases are also observed near this location, slightly away from the borehole. The resistivity decreases are probably directly caused by the reduction in DNAPL. During ground water pumping, water with relatively low resistivity has probably replaced some of the DNAPL pockets as the high resisitivity DNAPL was removed. Along borehole LLNL-2, the fiber optic sensor at $43 \mathrm{ft}$ depth showed a slight increase in DNAPL concentration. We suggest that this increase reflects the "granularity" of the DNAPL distribution. Small DNAPL globules are moving through the silt layer (small pore size) along LLNL-2 and probably moving in and out of the sensors' field of view.

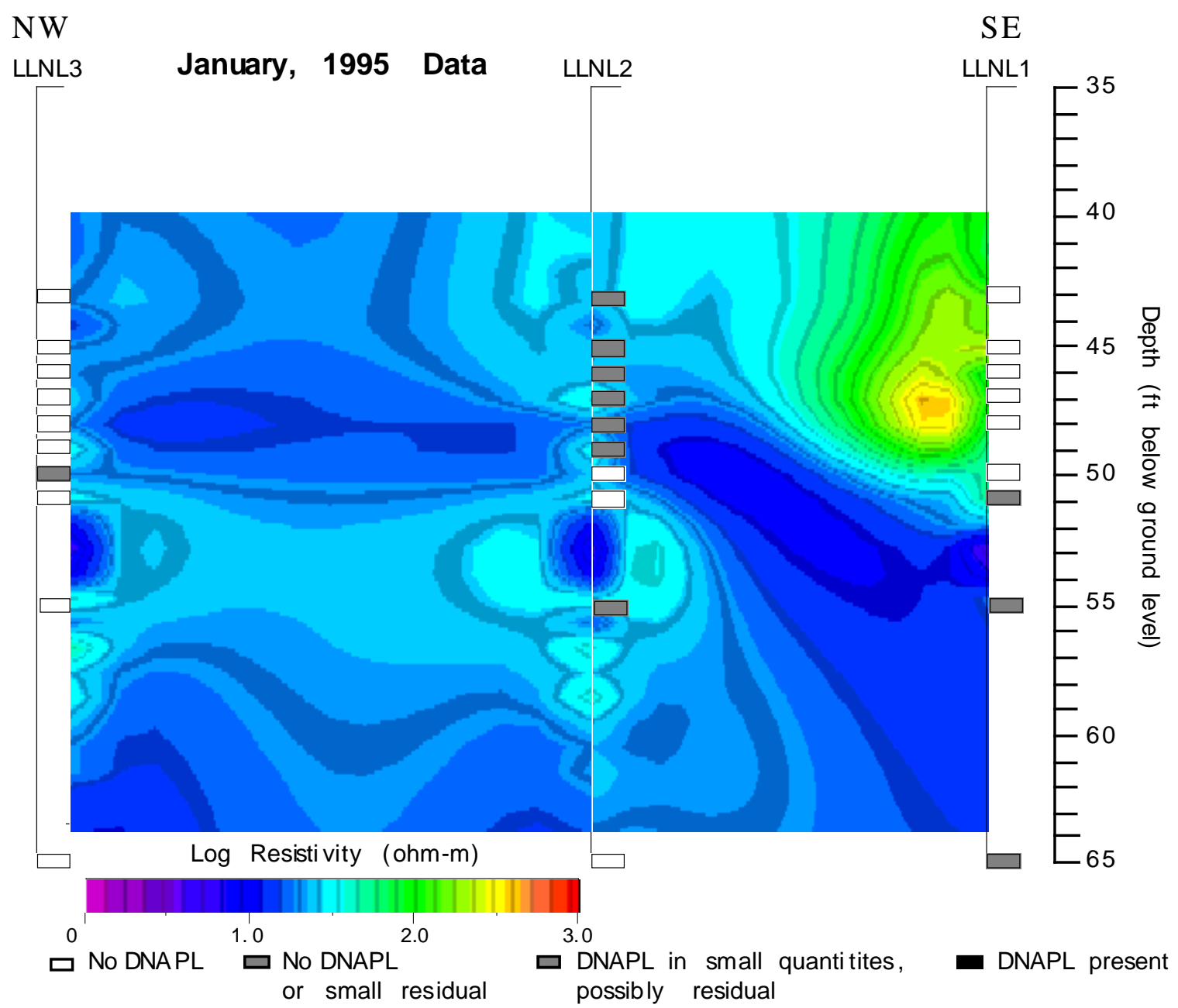

Figure 6a. ERT tomographs and fiber optic chemical sensor responses obtained in January, 1995. 


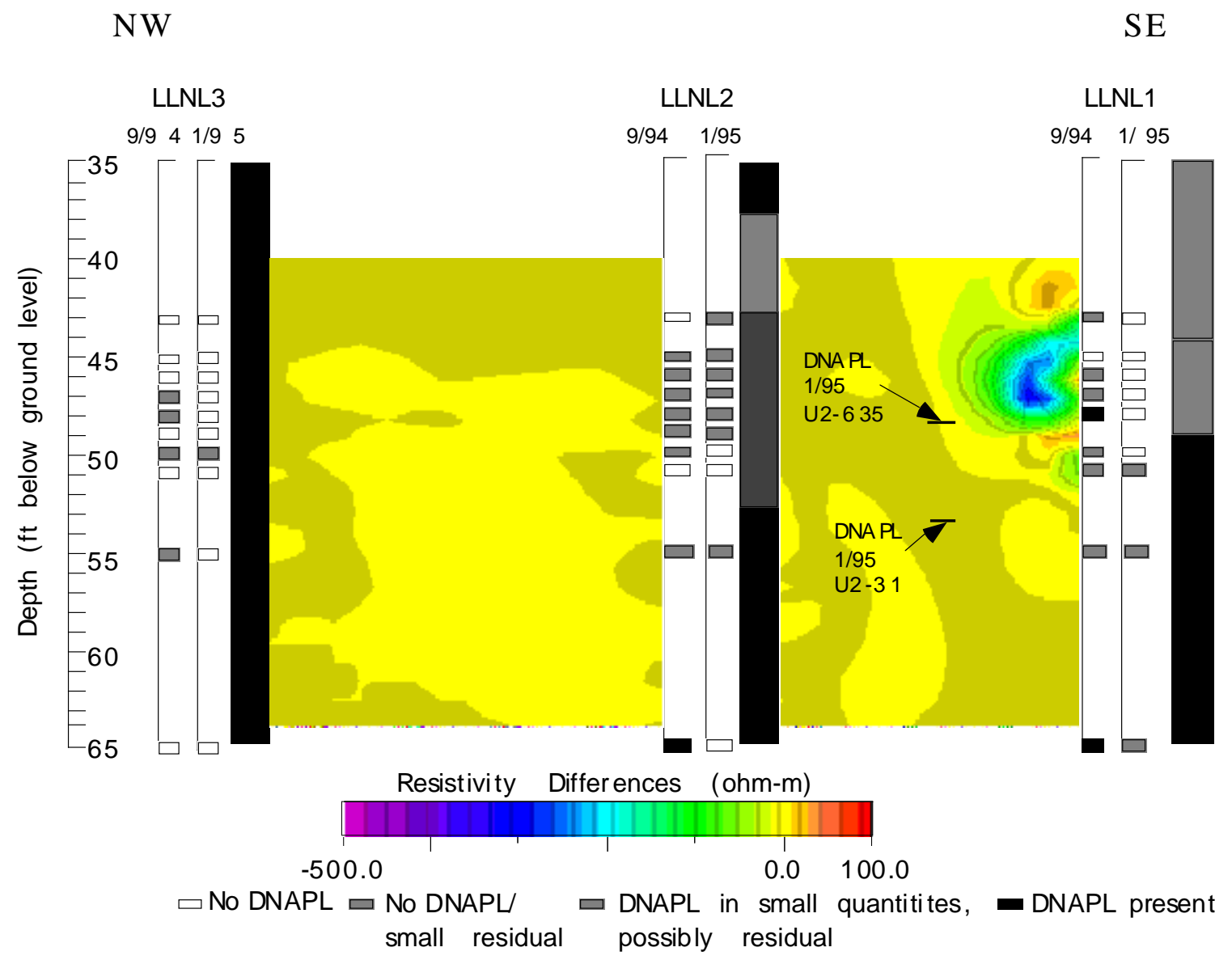

Figure 6b. Differences between data collected in January, 1995 and September, 1994.

Changes During Pumping: September, 1995 
From January, 1995 to September, 1995, over 2 million gallons of water were pumped and treated, with the recovery of another 700 gallons or so of DNAPL. A subsequent data set, collected in September, is shown in Figure 7. Electrical resistivities continued to decrease in the basin. The resistive anomaly is not only of diminished amplitude, however; its locus has shifted in an eastward direction (Figure 7a). In fact, its shape is no longer a bull's eye, and its "center" appears to have moved eastward beyond LLNL-1.

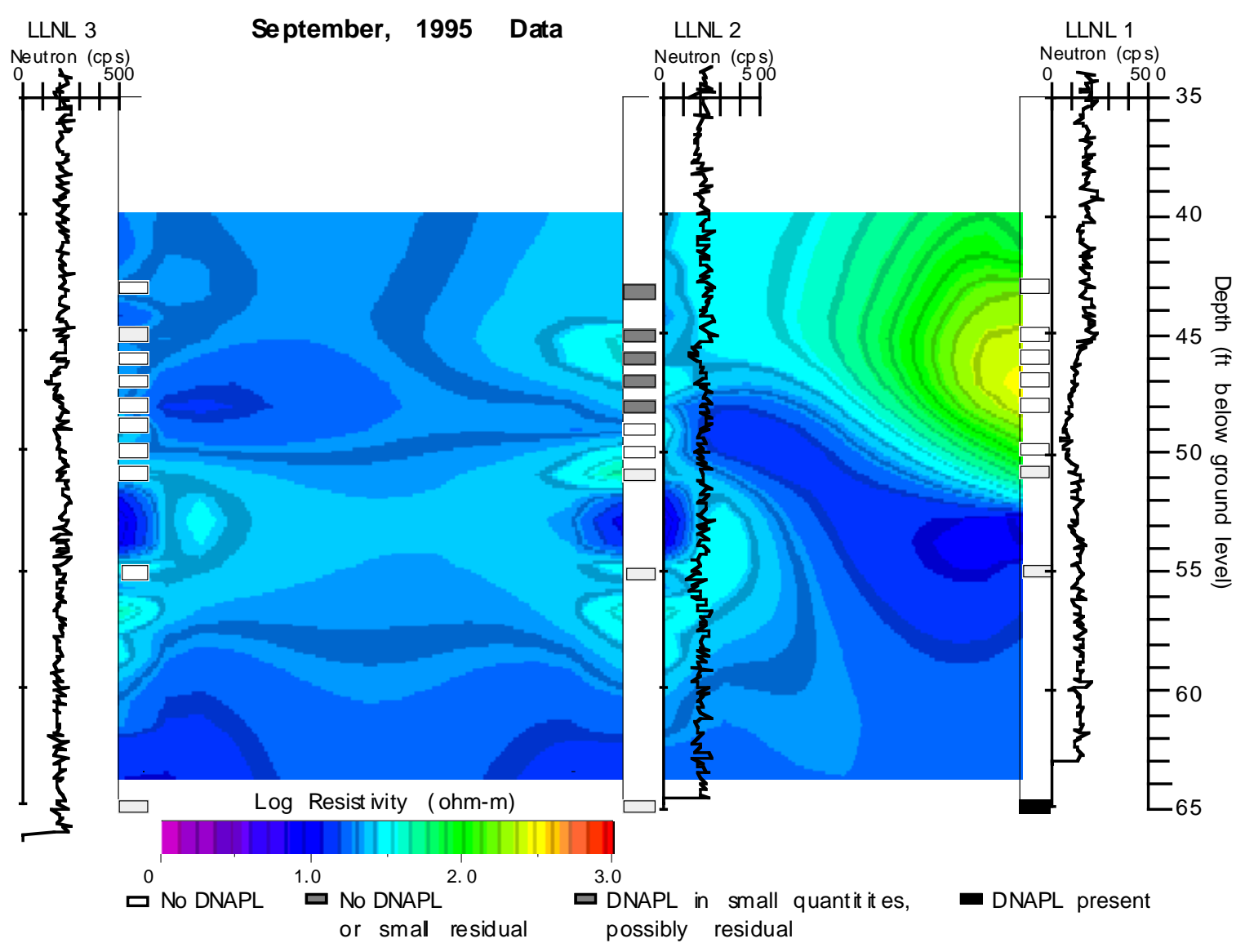

Figure 7a. ERT, neutron logs and fiber optic chemical sensor responses obtained in September, 1995.

Continued flushing of the DNAPL from the formation is indicated by the fiber optic sensors along LLNL-1. Indications of small or residual quantities of DNAPL above $47 \mathrm{ft}$. persist in the vicinity of LLNL-2. The neutron log in LLNL-1 continues to show a broad interval of low counts from about 45-51 ft, coincident with the interval of high resistivity along the borehole. This suggests that considerable product remains in the formation despite the clean fiber optic readings at the borehole. A small interval of lower neutron counts in LLNL-2 appears at about 45.5-47 ft depth. This occurs within the interval in 
which the fiber optic sensors indicate small or residual quantities of DNAPL present. There are no such features present in the LLNL-3 neutron log. 
Differences between data collected over a year's duration reveal total changes through the basin during pumping (Figure 7b). In general, the electrical resistivity diminished substantially in the bull's eye region. A striking resistivity increase along LLNL-1 is an artifact produced when the locus of the resistive anomaly moves eastward, increasing the resistivity over its September, 1994 values. Overall, a considerable flushing of the formation has been accomplished, but indications of DNAPL persist.

NW

LLNL3

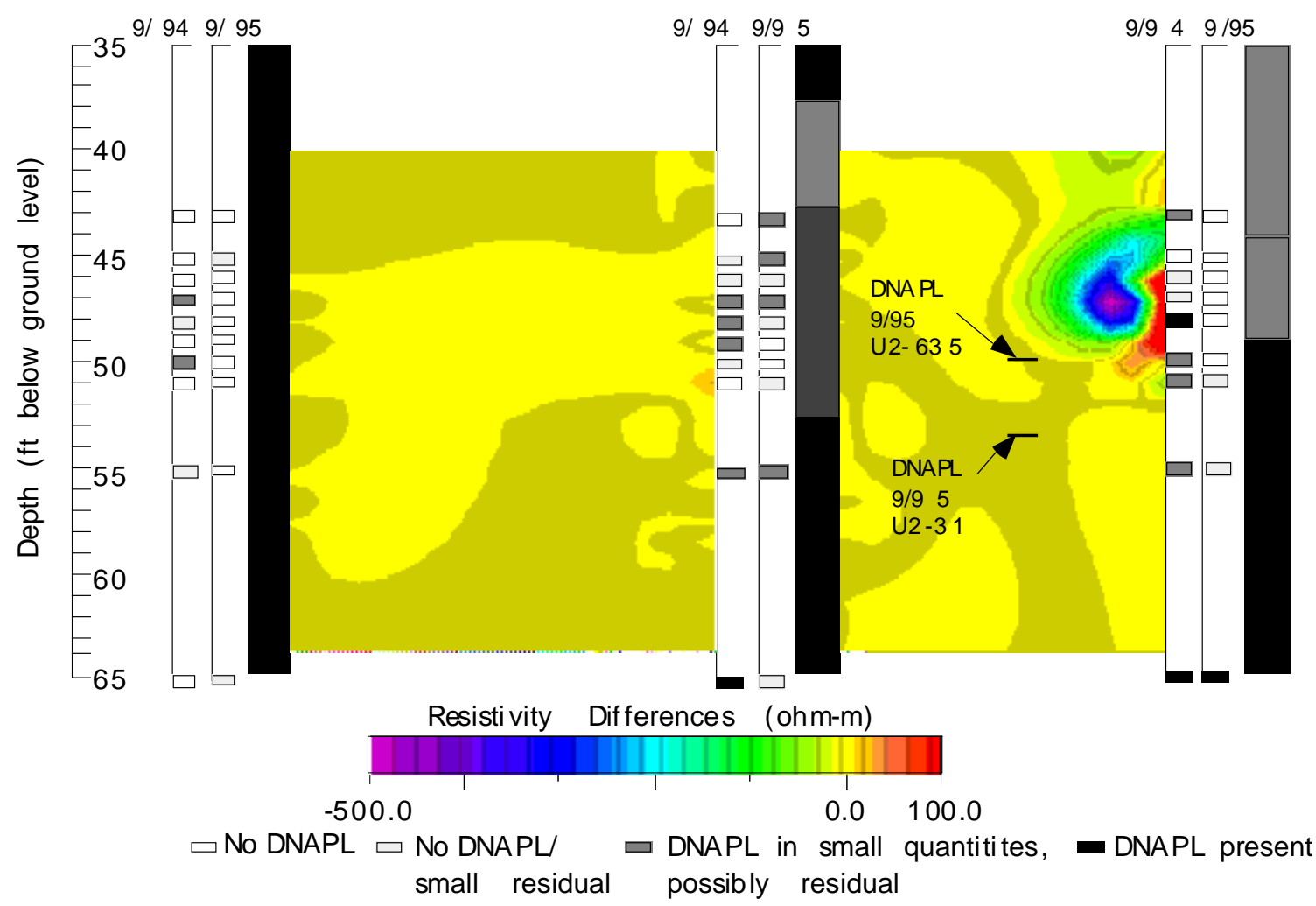

Figure 7b. Differences between data collected in September, 1995 and September, 1994.

By differencing the September, 1994 neutron counts from the logs obtained in September, 1995, we can assess the total change in neutron character over the period of a year. Since the base values are offset by about 200 counts due to initial calibrations, only the relative changes are meaningful. The total changes over the period of a year show a few zones which experienced an increase in neutron counts (by as much as 200 counts). The largest such zone is in LLNL-1 from 47-57 ft. depth (Figure 8). In LLNL-2, there are three short intervals which experienced an increase in neutron counts over the year; 37-41 ft., 48-49.5 $\mathrm{ft}$. and 56-59 ft. The neutron logs in LLNL-3 show no significant change; the slight increase in counts at about $47 \mathrm{ft}$. is not much above the noise level. It is interesting to note that this feature, if real, occurs just above the spoon-shaped conductive feature interpreted to be a barrier to downward flow. 

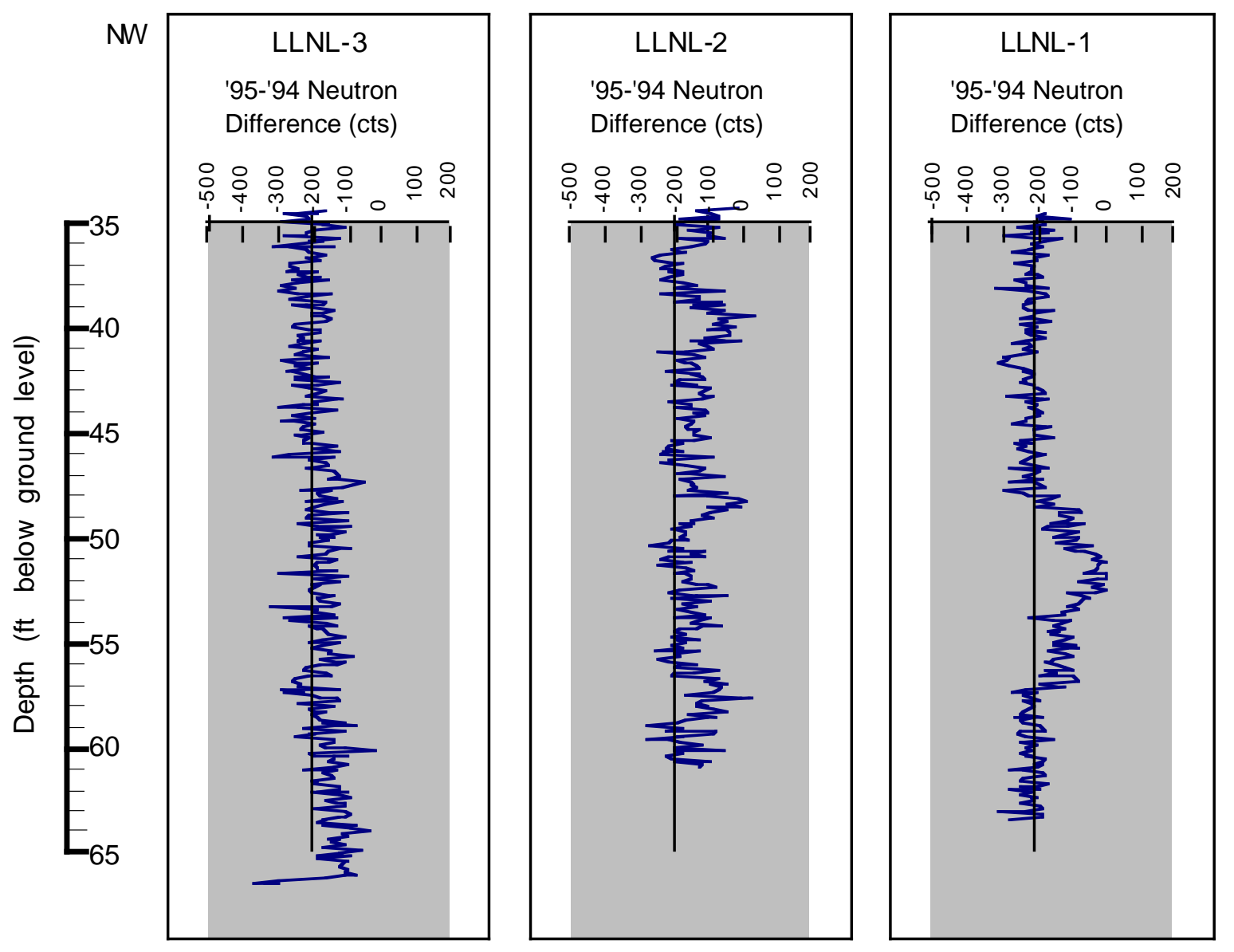

Figure 8. Differrences in neutron counts expressed as (September '95 log values) (September '94 values). Due to a difference in intial calibrations, there is a constant offset of approximately 200 counts between the two sets of logs.

\section{Discussion}

The ERT difference images provide a 2-dimensional view of the zone in which DNAPL is being removed from the ground and replaced by ground water over time. This interpretation is supported by the fiber optic sensor results, which indicate changes in ground water chemistry at individual points along the boreholes. DNAPL is being pumped from a well located to the north along the axis of the aquifer, roughly midway between LLNL-1 and LLNL-2 and out of the image plane. The changes mainly occur within the sandy aquifer, while the DNAPL levels are monitored at greater depth in U2-31. We suggest that the DNAPL flows along the top of the aquitard (the conductive unit seen at about $50 \mathrm{ft}$ depth in LLNL-1) toward U2-31 as into a sump. Once the collected DNAPL is removed, DNAPL migration along the aquitard's surface controls the recovery observed in the pump well (Figure 9). At U2-635 (just north of LLNL-1), DNAPL is observed in 
the aquifer and levels drop mainly at the end of a pump cycle. We expect this is a response to DNAPL drainage as the collected product in the sump is removed.

It is interesting to note the magnitude of the resistivity changes detected in the basin after a relatively modest amount of DNAPL had been removed. The removal of 643 gallons of DNAPL between September, 1994 and January, 1995 represents a small fraction of the available pore space in the aquifer. The electrical resistivity in the basin dropped by as much as 300 ohm-m in the vicinity of LLNL-1. This represents a decrease of about $50 \%$. The total resistivity decrease in the basin during the year was over 500 ohm-m, representing a change of over $70 \%$.

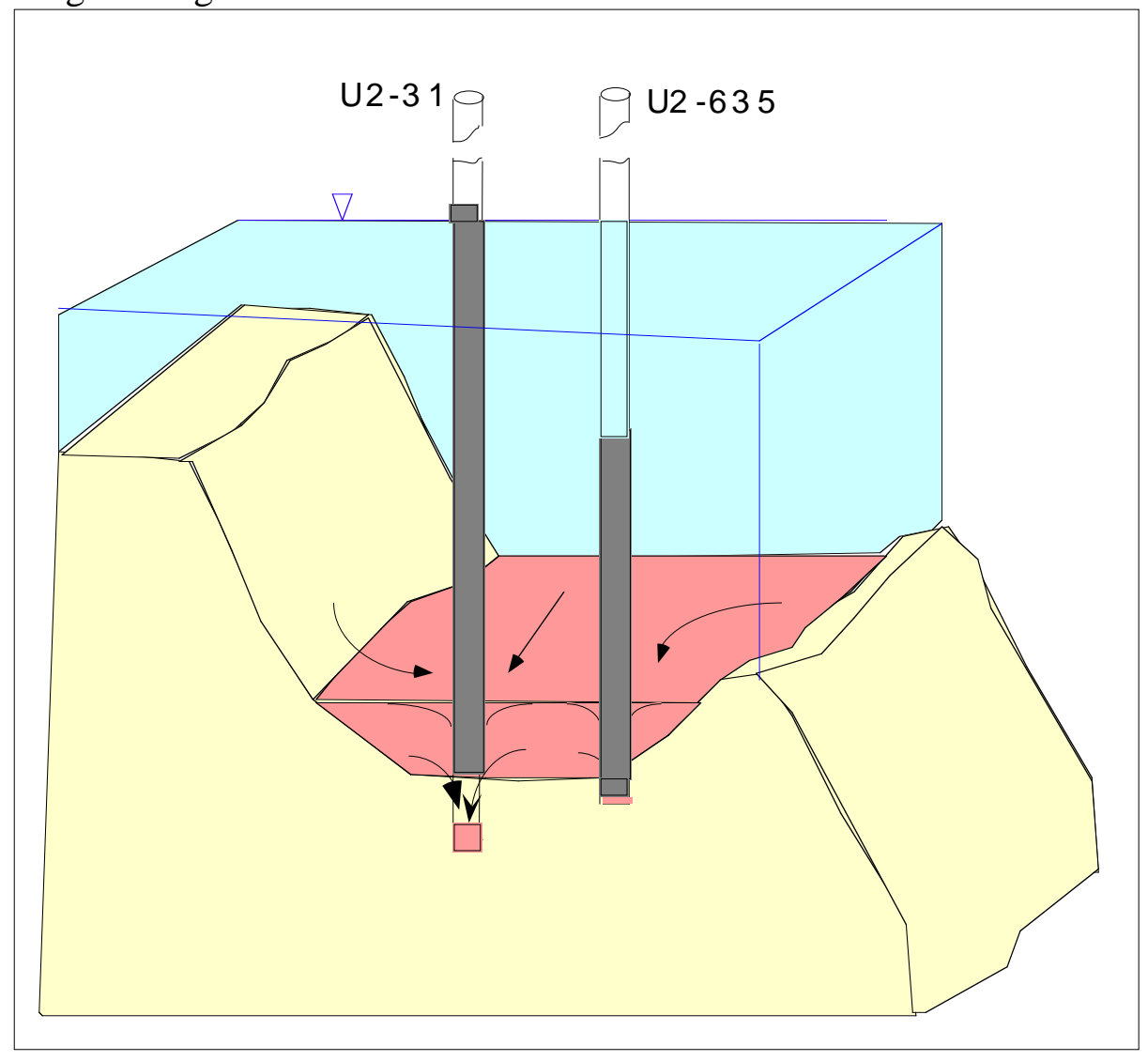

Figure 9. Conceptual view of DNAPL drainage at OU 2. Despite substantial flushing of the DNAPL, drainage is slow, and residual DNAPL persists.

One of our original goals was to determine if ERT could be used to characterize free product DNAPL concentrations without the need to compare two data sets - from absolute instead of comparison images. A simple strategy is to locate the DNAPL at the wellbore using fiber optic sensors, identify a resistive anomaly associated with the electrically insulating DNAPL, and map that resistive anomaly (and thus the DNAPL plume) between the wells. Key targets would include resistive anomalies (DNAPL saturated zones) adjacent to, but just above, conductive anomalies (silts or clays). The rational is that the resistive DNAPL would be expected to sink until coming to rest on a confining layer which is commonly more electrically conductive. Although this strategy relies on 
"circumstantial" evidence and not direct detection to map the plume, it seems a reasonable start, and can be tested using the results in Figure 5a.

According to the fiber optic sensors, there is unambiguous DNAPL at $47 \mathrm{ft}$ depth in LLNL-1. The ERT images show only one strong resistive anomaly and it is centered at that depth adjacent to LLNL-1. The sensor data show no DNAPL in LLNL-2 or LLNL-3 and the ERT anomaly does not extend to LLNL-2 or LLNL-3. The ERT anomaly lies above a conductive anomaly just as might be expected for a DNAPL pooled on top of a confining clay. We interpret the indications of small or residual DNAPL concentrations from the fiber optic sensors in LLNL-2 and LLNL-3 at the 47 and $45 \mathrm{ft}$ levels as residual globules of DNAPL left from drainage along the sloping confining layer indicated by the low resistivity zone in the ERT image directly below those DNAPL hits.

In short, the absolute image in Figure 5a meets the criteria we had originally proposed using to map DNAPLs with ERT. We would not be far from the interpretation based on resistivity differences if the original strategy had been used blindly to interpret the ERT data. The shape and magnitude of the resistive anomaly is more consistent with the residual DNAPL saturation draining into a pool. Using additional information regarding the range of resistivities expected given the lithology present at the site, it should be possible to discriminate between naturally-occurring high resistivity materials and potential DNAPL targets for further investigation. These potential DNAPL regions can then be investigated further using other means such as neutron logs, core sampling and analysis.

\section{Summary}

The removal of DNAPL during pumping has been monitored using integrated in situ geophysical techniques. The combined use of point sensors, geophysical logs and tomographic techniques is effective at detecting changes in the basin resulting from DNAPL removal, and in mapping these changes between boreholes. The fiber optic chemical sensors and geophysical logs were used to verify the lithology and chemistry near the boreholes. The ERT baseline images map the zone in which DNAPL is present between boreholes. The ERT difference images provide 2-dimensional views of the zone in which DNAPL is being replaced by ground water over time. The results of this study, coupled with hydrologic information from nearby wells, suggest that, as DNAPL is pumped from nearby U2-31, product slowly moves above the aquitard and into U2-31, where it collects. Although the fiber optic sensors indicated substantial flushing of DNAPL in the ground, the continued DNAPL level recovery in pumping well U2-31 and the nearly stable levels in U2-635 attests to the slow DNAPL drainage in the aquifer during the monitoring interval. In particular, the ability to extend our knowledge of the subsurface response between boreholes using ERT has led to an increased understanding of the basin's response to ground water pumping.

\section{Acknowledgments}

The success of this project resulted from the efforts of a number of people. Kyle Kirchner and Steve Hicken of Hill Air Force Base coordinated and supported the site visits. Curt Himle of Radian Corp. greatly facilitated the field activities. John Carbino and Paul 
Gronner (LLNL) coordinated the installation and construction of the borehole instruments. This work was performed under the Environmental Technologies Program at LLNL. Funding for this work was provided by Hill Air Force Base, Utah. Work performed under the auspices of the U.S. Department of Energy by Lawrence Livermore National Laboratory under Contract W-7405-ENG-48.

\section{References}

Daily, W., A. Ramirez, D. LaBrecque and J. Nitao, 1992. Electrical Resistivity Tomography of Vadose Water Movement, Water Resources Research, vol. 28, no. 5, pp1429-1442.

Newmark, R.L., S. Boyd, W. Daily, R. Goldman, R. Hunter, D. Kayes, K. Kenneally, A. Ramirez, K. Udell, and M. Wilt, 1994. Using geophysical techniques to control in situ thermal remediation, Symposium on the Application of Geophysics to Engineering and Environmental Problems (SAGEEP) '94, Boston, Ma., March 2731, 195-211.

Oolman, T., S. T. Godard, G.A. Pope, M. Jin and K. Kirchner, 1995. DNAPL flow behavior in a contaminated aquifer: evaluation of field data, Ground Water Monitoring Review 15, no. 4: 125-137.

Radian Corp. 1992. Remedial Investigation Report for Operable Unit 2. Contract No. F33615-90-D-4013, DO05. Utah: Hill Air Force Base.

Radian Corp. 1993. Addendum to the Remedial Investigation Report for Operable Unit 2. Contract No. F33615-90-D-4013, DO05. Utah: Hill Air Force Base.

Ramirez, A., W. Daily, K. LaBrecque, E. Owen and D. Chesnut, 1993. Monitoring an Underground Steam Injection Process Using Electrical Resistance Tomography, Water Resources Research, vol 29, no. 1.

Ramirez, A., W. Daily and R. L. Newmark, 1995. Electrical resistance tomography for steam injection monitoring and process control, JEEG, vol 0, no. 1, p. 39-51. 


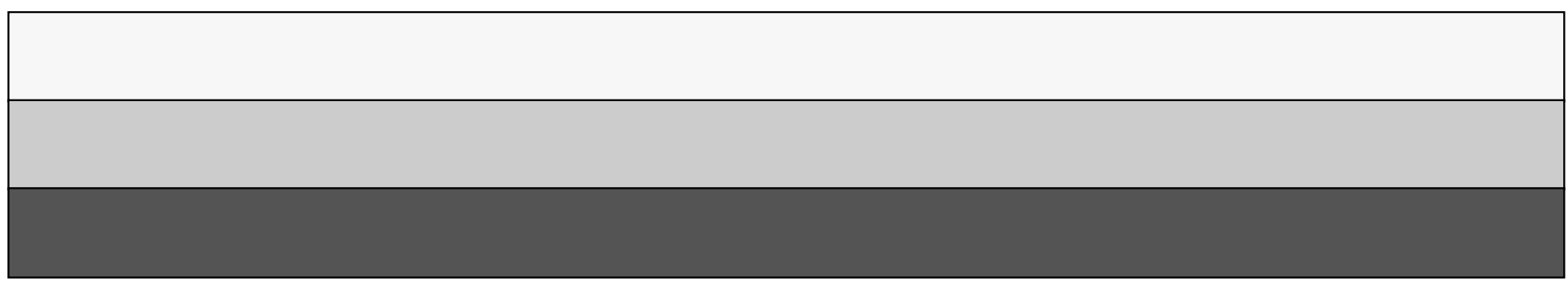

